\title{
History of the crest and motto of the Canadian Anesthesiologists' Society
}

\author{
Brendan T. Finucane, MBBCh, FRCPC, FRCA® $\cdot$ Derek Dillane, MBBCh, FCARCSI
}

Received: 4 August 2017/Revised: 18 September 2017/Accepted: 3 October 2017/Published online: 14 December 2017

(C) Canadian Anesthesiologists' Society 2017

In 1920, Dr.Wesley Bourne, a lecturer in pharmacology and an anesthetist at McGill University, organized the original Canadian Society of Anaesthetists. Dr. Bourne was a scholar of the Classics and designed the Society's inaugural crest. After merging with the Canadian Medical Association in 1927, the Canadian Anaesthetists' Society was again incorporated as an independent organization in 1943. This new organization adopted the crest and motto of the original Society.

The original crest of the Society (Figure a) was reproduced on a commorative plaque (not shown). The plaque was accompanied by a legend, which read as follows:

"This emblem depicts the home of the mythical god Hypnos. At the time of the organization of the Canadian Society of Anaesthetists in 1920, the artist, A. Sherriff Scott, RCA was asked to represent poppies on one side of the cave and a collection of roots and bark on the other. Side by side with these he took it upon himself to display the thistle and explained that, being a Scotsman, he could not withstand the temptation. It has since been suggested that, as the poppy produces sleep, the pricking of the thistle may cause arousal."

The motto, depicted in Greek, katheudontas parateroumen, is interpreted to mean "we watch closely

B. T. Finucane, MBBCh, FRCPC, FRCA ( $₫)$.

D. Dillane, MBBCh, FCARCSI

Department of Anesthesiology and Pain Medicine, University of

Alberta, Edmonton, AB, Canada

e-mail: bfinucan@ualberta.ca; btfinuc@shaw.ca;

bfinucane6@gmail.com those who sleep." The inspiration for the motto was attributed to Dean Moyse of McGill University.

A new crest and motto of the Canadian Anesthesiologists' Society (Figure b) were introduced in 1999 in an effort to enhance public awareness of the role of the specialty of anesthesia in Canada. The term anesthesiologist was thought to indicate more clearly that anesthesiologists were physicians. The Canadian Anaesthetists' Society thus became the Canadian Anesthesiologists' Society, with the diphthong deleted.

The reference to Hypnos and the motto in Greek letters were reconsidered in a further concession to our modernized society. After vigorous debate, the red maple leaf crest with an Aesculapian staff in purple was chosen. The new motto became: Science Vigilance Compassion in both English and French.

Information for this manuscript was drawn from the History of the Canadian Anesthesiologists' Society website. $^{\text {A }}$

\footnotetext{
$\bar{A}$ Canadian Anesthesiologists' Society. History of Canadian Anesthesiologists' Society. Available from URL: https://www.cas. ca/English/History-of-CAS (accessed September 2017).
} 
Figure (a) Design of the original crest and motto of the Canadian Society of

Anaesthetists. The original plaque is one of a number of Canadian Anesthesiologists' Society (CAS) artifacts owned by the CAS. (b) Canadian Anesthesiologists' Society new crest, approved by the CAS Executive in 1998 and adopted in 1999
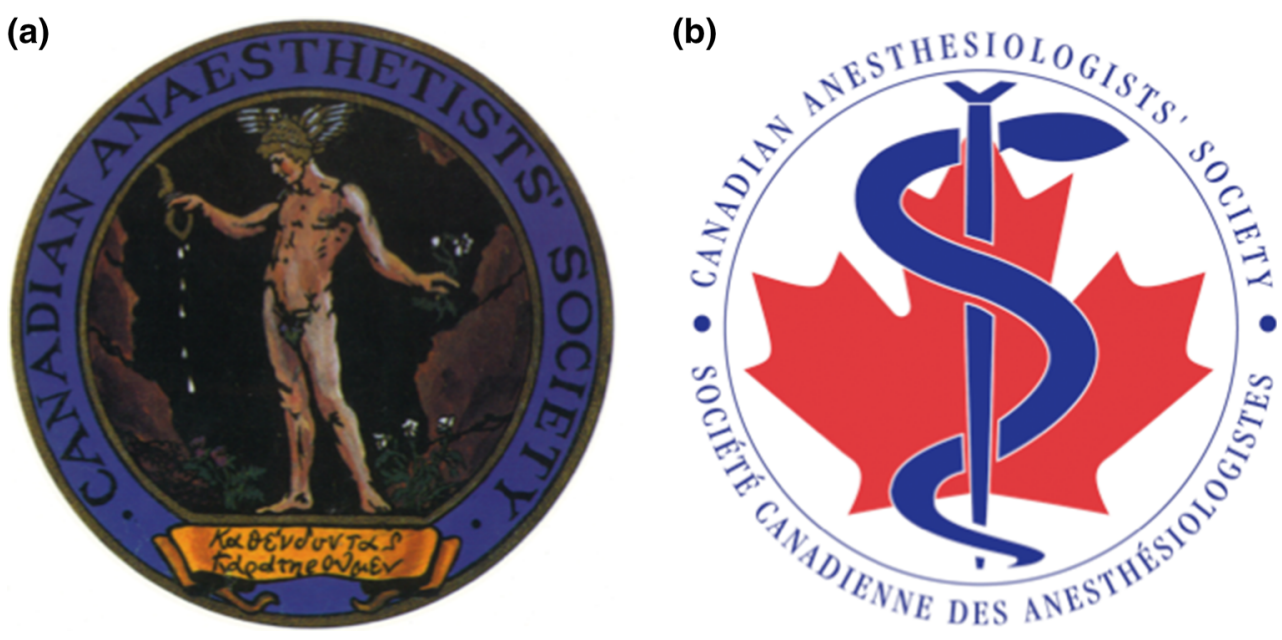

Conflicts of interest None declared.
Editorial responsibility This submission was handled by Dr. Gregory L. Bryson, Deputy Editor-in-Chief, Canadian Journal of Anesthesia. 